Terrone, Enrico (forthcoming, acceptance date: 20 January 2020)

"The Standard of Correctness and the Ontology of Depiction", American Philosophical Quarterly, 58.4 


\title{
The Standard of Correctness and the Ontology of Depiction
}

\begin{abstract}
This paper develops Richard Wollheim's claim that the proper appreciation of a picture involves not only enjoying a seeing-in experience but also abiding by a standard of correctness. While scholars have so far focused on what fixes the standard, thereby discussing the alternative between intentions and causal mechanisms, the paper focuses on what the standard does, that is, establishing which kinds, individuals, features and standpoints are relevant to the understanding of pictures. It is argued that, while standards concerning kinds, individuals and features can be relevant also to ordinary perception, standards concerning standpoints are specific to pictorial experience. Drawing on all this, the paper proposes an ontology of depiction according to which a picture is constituted by both its visual appearance and its standard of correctness.
\end{abstract}

\section{TEXT}

What is a picture? Experience-based theories of depiction (e.g. Wollheim 1980, Hopkins 1998) conceive of pictures as marked surfaces that elicit a sui generis perceptual experience. Likewise, according to recognitional theories (e.g. Schier 1986, Lopes 1996), a picture is a marked surface that triggers perceptual recognition of its subject from a suitable viewer. Experience-based theories and recognitional theories cast pictures as artifacts whose function consists in eliciting a sort of secondhand perception which, borrowing Richard Wollheim's (1980) expression, one might call "seeing-in".

Still, as acknowledged by both experience-based theorists and recognitional theorists, seeing-in cannot be the whole story. There is another element that essentially contributes to depiction. This is what Wollheim (1980) calls "the standard of correctness", that is, the norm that seeing-in should abide by in order to count as an appropriate appreciation of what is depicted. While seeing-in is elicited by the 
picture's appearance, the standard of correctness is established by the picture's history.

Much theoretical effort has been devoted so far to figure out seeing-in while the standard of correctness has been discussed almost exclusively with respect to the distinction between intentional and causal factors. Specifically, scholars tend to trace the standard of correctness back to two sources: the maker's intentions in the case of handmade pictures, and causal mechanisms in the case of photographs (see Newall 2011a and 2011b, pp. 55-61). However, intentions also can contribute to fix the standard for photographs (see Hopkins 1998, pp. 71-77), as well as causal mechanisms can help to fix standard for handmade pictures (see Lopes 1996, pp. 164-165).

In the first part of this paper (sections 1-4), I will highlight a more basic distinction, which concerns what the standard of correctness does rather than what fixes it. This is the distinction between four different ways in which the standard of correctness can operate, namely, with respect to kinds, individuals, standpoints, and features. I will dub them the kind-standard, the individual-standard, the standpoint-standard, and the feature-standard. I will elucidate them thereby building up a thorough account of the standard of correctness.

In the second part of the paper (sections 5-8), I will draw on the notion of standard of correctness in order to propose an ontology of depiction, that is, a fully fledged answer to the question "what is a picture?". Specifically, I will argue that a picture is an artifact which is constituted by both its marked surface and its standard of correctness. While the marked surface plays the role of material constituent, the standard of correctness rather plays the role of constitutive norm.

\section{Individuals and Kinds}

As pointed out by Wollheim (1980), the visual experience elicited by a picture, namely seeing-in, is necessary but not sufficient for an appropriate appreciation of the picture. The reason is that seeing-in only provides us with a visual appearance that might correspond to several things. Thus, in order to 
properly appreciate a picture, one needs to pick out what is depicted among the various things that one can see in that marked surface. Here is where the standard of correctness enters the picture. As Wollheim (1980, p. 137) puts it, "What the standard does is to select the correct perception of a representation out of possible perceptions of it".

Still, Wollheim's characterization faces two issues. First, it presupposes some conceptual penetration of perception, so that a grasping of the standard can change the perception of what is depicted. However, it is controversial whether perception can be conceptually penetrated, and thus it would be better to avoid such presupposition (see Firestone and Scholl 2016). A more neutral formulation is thus preferable, according to which what the standard does is to select the correct understanding of a representation out of possible understandings of it. While seeing-in provides us with a bundle of possible understandings of a picture, the standard of correctness allows us to select the correct one out of them.

Secondly, Wollheim focuses almost exclusively on what I have dubbed "individual-standard" and "kind-standard", thereby underestimating the "standpoint-standard" and the "feature-standard". In fact, focusing on what he says on individuals and kinds can help us to see both the strengths and the limitations of his account.

Wollheim (1980, p. 138) begins with observing that the standard "applies both to representations of particular things and to the representations of things of a particular kind". Then, as a paradigmatic kind-standard, he considers "a certain sixteenth-century engraving, ascribed to a follower of Marcantonio" in which "some art-historians have seen a dog curled up asleep at the feet of a female saint", and yet "Closer attention to the subject, and to the print itself, will show the spectator that the animal is a lamb" (1980, p. 138). Lastly, as a paradigmatic individual-standard, he mentions "Holbein's famous portrait in three-quarters view", observing that "I normally see Henry VIII. However, I may have been going to too many old movies recently, and I look at the portrait and, instead of seeing Henry 
VIII, I now find myself seeing Charles Laughton" (1980, p. 138).

Both the individual-standard and the kind-standard are fixed by the picture's history and constrain the viewer's experience. As Wollheim (1980, p. 138) points out: "In each of these two cases there is a standard which says that one of the perceptions is correct and the other incorrect, this standard goes back to the intentions of the unknown engraver or of Holbein, and, in so far as I set myself to look at the representation as a representation, I must try to get my perception to conform to this standard". Specifically, in the the sixteenth-century engraving, the kind-standard establishes that what the viewer sees in the picture belongs to the kind "lamb", not to the kind "dog", while in Holbein's portrait, the individual-standard establishes that the individual to be seen in the picture is Henry VIII, not Charles Laughton.

While the individual-standard often needs to be explicitly stated since our knowledge of individuals is necessarily limited, the kind-standard usually remains implicit in practice since identification of kinds such as human being or tree or star are part of the basic knowledge we share as members of our form of life. Yet, the fact that the standard is obvious and taken for granted does not mean that there is no standard. If one imaginarily shifts the context, the hidden standard can show up. Let us consider, for instance, a hypothetical alien viewer who lacks the concept of a certain kind thereby failing to correctly understand a painting which portray an individual of that kind. In fact, we can find ourselves in a similar situation when we face pictures of things whose kinds we find it hard to detect. Susan Sontag (1977, pp. 71-72) offers a couple of interesting examples of the situation in which the kind-standard can no longer be taken for granted: “The subject of Weston's 'Cabbage Leaf,' taken in 1931, looks like a fall of gathered cloth; a title is needed to identify it. [...] What looks like a bare coronet- the famous photograph taken by Harold Edgerton in 1936 - becomes far more interesting when we find out it is a splash of milk". Wollheim's above mentioned example of the sixteenth-century engraving that seems to portray a dog but in fact portrays a lamb provides us with an analogous case in the domain of 
handmade pictures. ${ }^{\mathrm{i}}$

At this point, one might wonder whether any picture has both an individual-standard and a kindstandard. That sounds too demanding. For many pictures, the individual-standard seems to be dispensable. An appropriate experience of Francisco Goya's "The Third of May 1808", for instance, does not require that one knows the identity of all the persons depicted. What matters in this case, as suggested by the title, is rather the correct identification of where and when the scene depicted occurs. An appropriate understanding of this painting surely requires that one treats that event as occurring in Madrid at the date specified by the title. Likewise, an appropriate understanding of Auguste Renoir's "Bal du moulin de la Galette" does not require that the viewer knows the identity of all the persons depicted. The standard of that painting only requires that one treats that dance as occurring in Paris in the 1870 s. Treating that dance as occurring, say, in Naples in the 1830 s would be compatible with the seeing-in experience elicited by that painting but not with its standard of correctness. In the next section, I will argue that such standard concerning places and times, namely the standpoint-standard, is specific to the pictorial experience whereas the requirements on kinds and individuals can also apply to ordinary perception.

\section{Standpoints and Features}

If one shows me something to see, my response can be evaluated with respect to a sort of standard of correctness even though mine is an episode of ordinary perception instead of pictorial experience. If one shows me a lamb over there but I wrongly see it as a dog, my response is inappropriate with respect to a sort of kind-standard. Likewise, if one shows me Queen Elizabeth II over there but I mistake her for actress Helen Mirren, my response is inappropriate with respect to a sort of individualstandard. In this sense, both the kind-standard and the individual-standard can also be applied to ordinary perception. Yet, in the latter, the place of the scene we see is here, in front of us, and the time 
when it occurs is now, when our very perception is occurring. The pictorial experience, instead, does not tell us anything about the place in which and the time at which the scene depicted occurs.

On the one hand, ordinary perception warrants that we perceive a certain scene from the standpoint occupied by our body. Thus, we are automatically informed about the place in which and the time at which the scene perceived occurs, namely, here (i.e. where our body is) and now (i.e. when our body is undergoing this experience). On the other hand, pictorial perception provides us with a perspective that does not correspond to the standpoint currently occupied by our body. Therefore, we need the standard of correctness in order to fix the place and the time of that standpoint. This is what I call the standpoint-standard, which selects the correct spatiotemporal location of the scene depicted out of possible spatiotemporal locations of it.

In the pictures supplied by surveillance cameras and CCTV systems the standpoint-standard surely play a key role. An appropriate understanding of what is depicted, indeed, requires that one knows where the surveillance camera is placed, as well as whether it is recording now or, if not, when it recorded the scene depicted. In fact, when one watches the pictures provided by surveillance cameras, the kind-standard and the individual-standard are as dispensable as they are in ordinary perception, in which one can see something moving over there without knowing what it is. However, the standpointstandard is indispensable. If one ignores the standpoint-standard, one is not properly understanding the scene depicted.

The standpoint-standard can also be relevant beyond surveillance cameras and CCTV systems. Digital cameras now typically include metadata specifying when and where (viz. date, time, longitude, latitude) a certain photograph was taken. In old analog photographs, a similar role was often played by the title. Consider Henri Cartier-Bresson's photograph "Juvisy, France. 1938", whose title tells us where and when the scene depicted is located. The same is true for many paintings. For instance, John Constable's "Beaching a Boat, Brighton" has a title that not only provides us with an indication of the 
kind of event that we should see in the picture (the beaching of a boat) but also specifies a place (Brighton), which one can somehow supplement with a time if one considers the year in which the painting was made (1824).

In addition to place and time, there is a third parameter that is crucial to the standpoint-standard, namely world. The latter specifies the spatiotemporal framework to which the relevant place and time belong. In photographs or in paintings that portray real people and events, the standpoint-standard specifies the spatiotemporal framework in which the picture itself, its maker, and its viewers have their place, namely, the actual world. Still, there are pictures whose standpoint is located in an alleged spatiotemporal framework, namely a fictional world, which can do without the picture itself, its maker, and its viewers.

For instance, Jacques-Louis David's “The Death of Marat” and Piero di Cosimo's “A Satyr Mourning over a Nymph" depict the same kind of event, namely death, and yet these paintings sharply differ as regards the standpoint-standard. The former locates the mournful event in the actual world, the latter in a fictional world. Likewise, in the case of moving pictures, the standpoint-standard draws the boundary between documentaries, whose standpoints are located in the actual world, and fiction films, which invite us to enjoy standpoints located in fictional worlds. ${ }^{\text {ii }}$

To sum up, pictures invite us to see certain individuals belonging to certain kinds from a certain standpoint. The standard of correctness tells us who those individuals are, which kinds they belong to, and which standpoint they have to be seen from. Still, in representing individuals, pictures also endow them with visual features. Such features are usually ascribed to the individuals depicted, but there might be exceptions. For instance, a black and white photograph endows the depicted individuals with black and white colors but does not ascribe such colors to them. In other words, the individuals looks black and white but we are not entitled to conclude that they are so colored. The role of the featurestandard precisely consists in distinguishing the features that are ascribed to the individuals depicted 
from those they are just endowed with.

Pictures such as black and white photographs inherit their feature-standard from the category to which they belong. Yet, there might be cases in which a pictures has a feature-standard of its own. For instance, the feature-standard of Parmiginanino's "The Madonna with the Long Neck" establishes that the length of the neck is not to be ascribed to the Madonna in spite of the fact that she is endowed with this feature. Likewise, Henri Matisse's "The Green Stripe" has not only an individual-standard according to which the person portrayed is Amélie Noellie Matisse-Parayre, the wife of the painter, but also a feature-standard according to which the green stripe that divides her face in half is not a sort of birthmark that we should ascribe to her. ${ }^{\text {iii }}$

Just as the individual-standard and the kind-standard, the feature-standard is not specific to pictorial experience. It can be found also in ordinary perception. When we see things in a room illuminated by a blue light, for example, we should be aware that those things are not blue even though they looks blue, just as Madame Matisse's face it is not green even though it looks green. The standpoint-standard, instead, as argued above, is unique to pictures.

\section{Indeterminacy, Interpretation, and Disagreement}

As said from the beginning, the four categories that I have highlighted - the kind-standard, the individual-standard, the feature-standard and the standpoint-standard-are not aimed to individuate different standard of correctness but rather different ways in which the standard of correctness can function. In principle, all the four categories can contribute to the standard of correctness of a given picture. For instance, the standard of "The Death of Marat" mandates us to see, from a certain standpoint (Paris, July 13, 1793), an event of a certain kind (death) involving a certain individual (Marat); moreover, it mandates us to ascribe certain features (the various colors and shapes, but not the inscriptions in the bedside table) to that scene. 
In sum, the four categories do not individuate four different ways of seeing pictures, but rather four different ways of supplementing the pictorial experience with non-pictorial information. Thus, I am not proposing a distinction between pictures in which we ought to see kinds, pictures in which we ought to see individuals, pictures in which we ought to see features, and pictures in which we ought to see a scene from a specific standpoint. Pictures usually mandate us to do all these things: we are invited to see, from a certain standpoint, individuals belonging to kinds and having features. The four different dimensions of the standard just tells us which is that standpoint, which are those individuals, which are their kinds, and which features we should ascribe to them. When the standard lacks some of those dimensions, the corresponding parameter remains indeterminate. For instance, the viewer of "Bal du moulin de la Galette" can see several individuals but cannot establish who they are. Yet, this does not mean that the viewer sees kinds instead of individuals. Indeed, she sees individuals in spite of not being capable to identify them. ${ }^{\text {iv }}$

The standard of correctness of a picture is not to be confused with an interpretation of it. The former governs the correct understanding of the picture and thus should be shared by all the viewers. An interpretation, instead, can be accepted by some viewers and rejected by others in spite of the fact that they all correctly understand the picture. One might say that the understanding governed by the picture's standard of correctness constrains possible interpretations just as the visual experience elicited by the picture's surface constrains possible understandings. Thus people can disagree on the interpretation of a picture while agreeing on its standard of correctness.

If the standard leaves some parameters indeterminate, however, disagreement about the standard of correctness can arise. This happens when the picture's appearance makes room for a bunch of plausible understandings but the information available about the picture's history is not sufficient to select one out of them with certainty. An interesting example, in this sense, is the philosophical controversy surrounding Vincent Van Gogh's painting “Shoes”, which Martin Heidegger (1964, pp. 662-663) sees 
as governed by a kind-standard: "In van Gogh's painting we cannot even tell where these shoes stand. There is nothing surrounding this pair of peasant shoes in or to which they might belong, only an undefined space. [...] A pair of peasant shoes and nothing more". Meyer Schapiro (1968) criticizes Heidegger's stance towards the painting, arguing that Van Gogh was living in town when he painted those shoes. He thus proposes an alternative kind-standard, namely city-dweller shoes instead of peasant shoes: "They are the shoes of the artist, by that time a man of the town and city" (Shapiro 1968, p. 204). Moreover, he introduces a sort of individual-standard, arguing that the shoes depicted belong to a particular individual, Van Gogh himself.

Schapiro's criticism of Heidegger is in turn criticized by Jacques Derrida (1987), who argues that, even if Van Gogh was living in town when he made that painting, this would not entail that he depicted the shoes of a city-dweller, let alone his own shoes. Indeed, living in town does not prevent a painter from remembering or imagining peasant shoes, thereby painting them. Derrida (1987, p. 261) also puts into question the basic kind-standard that both Shapiro and Heidegger presuppose: "For where do they both - I mean Schapiro on one side, Heidegger on the other - get their certainty that it's a question here of a pair of shoes?". Analyzing the shapes of the shoes, Derrida observes that they are quite similar; in particular, they seem to be both left shoes. If they really were meant to be so, the kind-standard would state that what is depicted are two things both belonging to the kind "left shoes", not one thing belonging to the kind "pair of shoes". Derrida's (1987, p. 274) conclusion is that, lacking definitive pieces of evidence, we should limit ourselves to apply the very general kind-standard "shoes" to this painting: "Quite simply these shoes do not belong, they are neither present nor absent, there are shoes, period".

I argue that Derrida's conclusion is too hasty. He is overlooking the standpoint-standard. These are not just "shoes, period". Rather, these are shoes that exist in a certain historical context on which the painting supplies a peculiar standpoint. Specifically, an appropriate experience of the painting requires 
that we see them as shoes located somewhere in Western Europe in the 1880s. The fact that we cannot establish whether these shoes constitute a pair-or whether they are peasant shoes or city-dweller shoes, or whether they belong to Van Gogh—does not prevent us from seeing them as shoes belonging to the historical context in which they were painted. Even in ordinary perception one might perceive two shoes from a certain standpoint without being able to establish whether they constitute a pair or not, whether they are peasant shoes or city-dweller shoes, and to whom they really belong. The difference is that ordinary perception fixes its standpoint — here and now — on its own, whereas pictorial experience can do so only if supplemented by the standpoint-standard.

\section{The Game of Depiction}

One can try to minimize the role of the standard of correctness, as Derrida does, and yet one cannot give it up completely. Even Derrida's radical conclusion, "there are shoes, period", still presupposes a kind-standard according to which what one sees in this painting belongs to the kind "shoes". The point is that the standard of correctness is not just a possible enrichment of our pictorial experience, but rather a constitutive element of the picture, which reveals itself to be a pair constituted by both a visual appearance and a standard of correctness.

A constitutive element is not to be confused with a causal factor. The latter just contributes to bring an entity into existence whereas the former contributes to make that entity what it is. That said, there is a broad consensus on the fact that a picture is constituted by its marked surface. At most, scholars disagree as regards whether the marked surface is to be understood as a material object or rather as an abstract structure of colors (see Davies 2010, Zeimbekis 2012). One might say that the former option holds true in the case of paintings and drawings whereas the latter holds true in the case of reproducible pictures such as art prints and photographs. However, this is not the question that is relevant for my essay. I'm just assuming that a picture is constituted by its marked surface without taking stance on 
whether this is a fully fledged case of material constitution or rather a case of what one might call "structural constitution". The question I am interested in is another one: is a picture constituted by nothing but its marked surface? In what follows, I shall defend a negative answer to this question. I shall argue that the standard of correctness also is a constitutive element of the picture. Surely, the standard does not constitute the picture in the same way the marked surface does. As seen above, the latter is a material or structural constituent of the picture. The former, instead, is a normative constituent of the picture, namely its constitutive rule.

The notion of constitutive rule has been introduced in the philosophy of law and in the philosophy of language to capture cases in which a rule (or a set thereof) does not limit itself to regulate a preexisting activity but rather makes that activity what it is (cf. Rawls, 1955, Searle 1969, Williamson 1996, García-Carpintero forthcoming). The rules that constitute games are paradigmatic in this respect. For instance, the rules of chess do not limit themselves to regulate a preexisting activity: they makes chess the game it is.

I argue that depiction also can be understood as a sort of game. Just as the rules of chess govern our use of the chessboard, the standard of correctness governs our use of the marked surface. There is, nevertheless, a crucial difference. The structure of the chessboard is the same for all chess matches, and so are the rules of chess, whereas each picture has its own marked surface and its own standard of correctness.

Drawing on Kendall Walton's (1990, p. 296) notion of “perceptual games of make-believe”, one might say that there is a general rule of depiction which mandates the viewer to see a scene in the marked surface. ${ }^{v}$ Yet, the game of depiction is more complex than that. Each picture has its own rule of the game, namely, its standard of correctness, which mandates us not only to see a scene in the surface but also to understand that scene in a specific way. 


\section{Pictures and Images}

Constitutive rules, which bring a new activity into existence, are traditionally contrasted with regulative rules, which just regulate a preexisting activity. One might thus object that the standard of correctness is not a constitutive rule but only a regulative one: there is a preexisting activity, seeing-in, which can be regulated by means of the standard of correctness. From this perspective, a picture is nothing but a marked surface that elicits a seeing-in experience, and the standard of correctness boils down to a pragmatic mechanism that governs our use of pictures without bearing upon their being.

First of all, this objection leads us stress that there are two games that one can play with marked surfaces. One can either limit oneself to enjoying the seeing-in experience elicited by the surface or one can aim to understand the picture by taking its history into account. I propose to call the former “image-game" and the latter "picture-game" vi

That said, my reply to the objection is that the main game we play with marked surfaces in our cultural practices is the picture-game, not the image-game. In the former game, the standard of correctness does not limit itself to regulate a preexisting activity. Instead, it constitutes a new activity, the picture-game, as distinct from the image-game.

The proposed distinction between image-game and picture-game presents an interesting analogy with David Kaplan's (1989) distinction between the "character" and the "content" of an indexical. ${ }^{\text {vii }}$ In Kaplan's terms, the pronoun 'I' has just one "character" (the person who is speaking, let me assume) but can have different "contents" depending on the contexts in which it is used. Likewise, I contend, a marked surface corresponds to just one image-game but can enable different picture-games. However, in our cultural practices, we do not usually individuate marked surfaces in the way we individuate indexicals. That is to say that we do not cast marked surfaces as communicative devices that we can use in different contexts in order to mean different things. We do not deploy the Mona Lisa in the way we deploy the pronoun ' $\mathrm{I}$ '. The latter is individuated by its character, as one can easily see by checking the 
entry 'I' in a dictionary. Yet, if one checks the entry 'Mona Lisa' in an encyclopedia, one finds not only a description of its visual appearance but also a careful presentation of its standard of correctness. This suggests that, from an ontological perspective, depictions, unlike indexicals, are not individuated by their Kaplanian character (the image-game), but rather by their Kaplanian content (the picture-game).

The idea that there are two distinct games that we can play with marked surfaces fits well with those phenomenological or epistemological accounts of depiction according to which there are two different kinds of things that we can see in a marked surface. For instance, Edmund Husserl (2005) and Lambert Wiesing (2009) distinguish between the depicted object, which is a mere three-dimensional appearance, and the depicted subject, which is instead what is "genuinely meant" (Husserl 2005, 26) by the presentation. Likewise, John Haugeland (1991) and John Kulvicki (2006) distinguish between two kinds of pictorial contents, namely, the "bare-bone content", which is shared by all the things that match the appearance elicited by the marked surface, and the "fleshed out content", which just picks out what is actually depicted.

Drawing on such insights, Bence Nanay (2018) and Regina-Nino Mion (2019) cast the pictorial experience as "threefold". Wollheim (1980) only individuates two experiential folds, namely, a configurational fold that represents the marked surface, and a recognitional fold that represents what is depicted. For Nanay and Mion, instead, the configurational fold is supplemented by two recognitional folds; one representing the Husserlian object and the other the Husserlian subject.

However, I will not take stance on whether the pictorial experience actually is threefold. The threefoldness I am interested in is ontological, not phenomenological. This means that there are three entities at stake in depiction. First, the marked surface as an entity individuated by its structure, just as a rock or a cloud. Second, the image as an entity individuated by its general function, which consists in eliciting the experience of a three-dimensional appearance. Third, the picture as an artifact individuated by its specific function, which consists in eliciting the experience of certain things (of a certain kind, 
having certain features, and seen from a certain standpoint) that are picked out by the standard of correctness. In principle, the marked surface, the image and the picture all are ontologically respectable entities. Yet, if we consider the role that depiction plays in our cultural practices, it is the picture that matters rather than the image or the marked surface.

The cultural priority of pictures over images becomes especially evident if one notices that, in our practices, two things can share the same visual appearance and yet be different pictures in virtue of having different standards of correctness. Let us consider, for example, the case of two pictures, $\mathrm{P}_{\mathrm{A}}$ and $\mathrm{P}_{\mathrm{B}}$, which portray two twins, $\mathrm{A}$ and $\mathrm{B}$, in the same posture on the same background. $\mathrm{P}_{\mathrm{A}}$ and $\mathrm{P}_{\mathrm{B}}$ are numerically distinct in spite of having an identical appearance. The reason is that the standard of $\mathrm{P}_{\mathrm{A}}$ casts $A$ as the individual depicted whereas the standard of $P_{B}$ casts $B$. Therefore, $P_{A}$ and $P_{B}$ are distinct pictures in spite of sharing the same appearance, that is, of being the same image.

A similar case can be found in Arthur Danto's $(1981,1)$ though experiment about a series of red squares which constitute distinct works of art in spite of sharing the same appearance. In particular, "a still-life executed by an embittered disciple of Matisse, called 'Red Table Cloth"” and "a painting of the Israelites Crossing the Red Sea" (Danto 1981, 1) are distinct pictures even though they are visually indiscernible. The ontological consequence of Danto's thought experiment is that what makes “'Red Table Cloth" and "the Israelites Crossing the Red Sea" two distinct pictures cannot be their appearance. Hence, what constitutes those pictures cannot boil down to their appearance. There must be a hidden, invisible constituent which—as argued earlier—is the standard of correctness.

\section{The Varieties of Depiction}

Depending on its standard of correctness, a picture can function in at least three different ways. First, a picture that only has a kind-standard and a feature-standard just provides us with information about the features of a certain kind. The illustrations that one can find in ornithology books are of this sort. 
Second, a picture that also has an individual-standard—-but lacks a standpoint-standard—provides us with information about the features of a certain individual regardless of the particular situations in which that individual might find herself. The photographs included in documents such as passports or identity cards are of this sort. Third, a picture having not only a kind-standard, a feature-standard and an individual-standard but also a standpoint-standard provides us with information about what is going on in a particular place at a particular time. The pictures provided by surveillance cameras and CCTV systems are of this sort.

The latter variety of depiction provides us with an experience which is close to ordinary perception inasmuch as it concerns particular individuals in particular circumstances, just as ordinary perception does. The former varieties of depiction, instead, are somehow intermediate between perception and conceptual thought (or language). Specifically, a picture such as a passport photograph, which has an individual-standard but lacks a standpoint-standard, provides us with a visual analogous of individual concepts (or proper nouns). And a picture such as those in ornithology books, which has a kindstandard but lacks a standpoint-standard, provides us with a visual analogous of generic concepts (or common nouns).

Even though some pictures may lack an individual-standard and a standpoint-standard, the kindstandard seems to remain an indispensable constituent of the vast majority of pictures. Indeed, one finds it hard to conceive of a picture to which no kind-standard applies. Perhaps some abstract paintings such as those by Joan Miro, Yves Tanguy, Paul Klee or Wassily Kandinski are of this sort. We just see things with certain shapes and colors but we do not know what kinds they belong to. Yet, in such cases, one might wonder if these pictures really depict something, i.e. these really are pictures and not just mere images such as those of Rorschach tests (see Wollheim 1980, p. 138). Thus, one is faced with two alternatives. 
If one denies that abstract paintings are pictures, these cannot count as counterexamples to the claim that pictures are constituted not only by a marked surface but also by a standard of correctness. For instance, according to Walton's account of nonfigurative art (1990, pp. 54-57)—inspired by Wollheim's (1974) — a work such as Kasimir Malevich's Suprematist Painting is an image since we can see a three-dimensional appearance in its two-dimensional surface, but it is not a picture since our experience of that appearance is not supplemented by anything. ${ }^{\text {vii }}$

On the other hand, if one treats abstract paintings as pictures, one is at least committed to the claim that these provide us with a perspective on a world different from ours, a world inhabited by individuals whose kinds we completely ignore. In this case, such pictures have at least a standpoint-standard, which prescribes us to treat what we see as occurring in a world that is different from the actual one.

At the end of the day, I do not intend to take stance on which option is the right one-I suspect that the answer depends in which particular abstract painting we are considering. I limit myself to pointing out that the proposed distinction between image-game and picture-game enables us to highlight two different ways — both aesthetically valuable, I would say-in which a viewer might engage with abstract paintings.

\section{The Secret Life of Pictures}

That something cannot be seen does not mean that it does not exist. If we conceive of pictures as artifacts whose functions consist in eliciting an appropriate experience from a suitable viewer, we should acknowledge that a picture is constituted not only by a visible component, namely its appearance, but also by a hidden component, namely its standard of correctness. Unlike the picture's appearance, which has its place in front of the viewer, the standard lacks a precise location in space, even though it has a beginning in time. The standard is not a visible thing but rather a norm that remains implicit in practice, and can be made explicit by means of texts such as titles, labels, catalogs, 
encyclopedia entries, or essays in art history. In principle, this norm is determined by the intentions of the maker of the picture or by the causal mechanism that produced it, depending on whether the picture is handmade or not.

Still, I contend, the standard of correctness that is actually in force for a picture - in a certain historical period, within a certain cultural community_-depends on the pieces of information possessed and by the attitudes adopted by the members of that community. If detailed information about the intentions of the maker or the circumstances of the relevant causal process is no longer available, the standard of correctness can be redefined by the members of the relevant community on the basis of the pieces of evidence that are at their disposal. What happens in such cases is the realistic version of a thought experiment suggested by Michael Newall (2011a, 4): "Imagine a community in which painters put their images to a popular vote in order to determine their meaning. Voters would be required to consider the various items that they find that each picture surface can occasion a visual experience or recognition of, and then choose one of these and write its name on a ballot. The picture's subject matter is then the item with the most votes".

Newall $(2011 \mathrm{a}, 4)$ treats this hypothesis as a merely theoretical conjecture, arguing that "To do away with a standard of correctness based on intention would be to make pictures much less useful to us. Understandably, this function is something that no culture that makes use of images appears to have sacrificed". Yet, it is a fact that there are pictures for which reliable information on the makers' intentions (or on the circumstances of the relevant causal processes) is no longer available. If we want to provide these pictures with standards of correctness on the basis of the few pieces of evidence that we possess, we should resort to some procedures of the sort imagined by Newall. Although we do not write our preferences on a ballot thereby selecting the standard of correctness with the most votes, we rely on an implicit negotiation that proceeds along similar lines and pursuits the same purpose. ${ }^{\text {ix }}$ The above mentioned debate on the shoes painted by Van Gogh can be seen as a negotiation of this sort. 
This leads us to stress the key role that art historians and art theorists play in the enforcement of the standard of correctness: they are the epistemic authorities to whom we defer the researches and negotiations aimed at establishing the standards of correctness of the pictures we live with. ${ }^{\mathrm{x}}$ For instance, the discipline that Erwin Panofsky (1955) calls "iconography” can improve our understanding and appreciation of pictures by highlighting their standard of correctness.

As the outcome of a negotiation, the standard of correctness rests upon the attitudes of the member of the relevant cultural community, as well as on the documents that have recorded them. If such attitudes and documents change, the standard of correctness changes in turn, and so does the picture that is constituted by it. This is not surprising, if we acknowledge that the standard of correctness is a public norm, and public norms can change over time, just as juridical laws do. Although, from an axiological perspective, we must consider the lost original standard of a certain picture more valuable — in virtue of its connection to the maker's intentions - than the one in force nowadays, from an ontological perspective the norm that actually constitutes the picture-game is the one currently in force, even though it is different from the original one.

\section{Conclusion}

Pictures can change in both their constitutive components. Just as the appearance of a picture can change as a consequence of changes of its material supports, the standard of correctness can change as a consequence of changes in the information possessed and in the attitudes adopted by the members of the relevant community.

In principle, the standard of correctness of a picture is easier to preserve than its visual appearance, since the former can be easily recorded in written documents whereas the latter may be embodied in delicate material objects such as painted canvas. However, the fact that the standard of correctness is an invisible component of a picture that usually remains implicit in practice can lead people to take it for 
granted thereby overlooking the possibility of losing it as time goes by. That being the case, a proper preservation of a picture should involve taking care not only of its visual appearance but also of its standard of correctness. In this sense, the art restorer and the art historian participate to the same enterprise, namely, preserving a picture. While the restorer takes care of the visual appearance of a picture, the historian takes care of its standard of correctness.

What holds true for preservation also applies to appreciation. As Nelson Goodman (1968, 111-112) aptly points out: "The aesthetic properties of a picture include not only those found by looking at it but also those that determine how it is to be looked at. This rather obvious fact would hardly have needed underlining but for the prevalence of the time-honored Tingle-Immersion theory, which tells us that the proper behaviour on encountering a work of art is to strip ourselves of all vestments of knowledge and experience (since they might blunt the immediacy of our enjoyment), then submerge ourselves completely and gauge the aesthetic potency of the work by the intensity and duration of the resulting tingle. The theory is absurd on the face of it and useless for dealing with any important problems of aesthetics; but it has become part of the fabric of our common nonsense".

If one considers the behavior and listens to the comments of the visitors of a gallery, one can notice that — half a century after the time when Goodman wrote these lines — the "Tingle-Immersion theory" still has a significant quantity of followers. In particular, it is quite common, when one visits an art gallery, to encounter visitors who are limiting themselves to looking at paintings, without caring at all about the standard of correctness. If what I have argued in this paper is right, such visitors fail in having an appropriate appreciation of the paintings they see. They mistake picture for images, thereby playing the wrong game in spite of being in front of the right chessboard. Surely art scholars are the most apt subjects to prevent such regrettable misunderstanding inasmuch as they are in charge of the preservation and communication of the standard of correctness. Still, philosophers also can contribute to improve our cultural practices involving pictures by showing how crucial the standard of correctness 
is to them. This is what I have tried to do in this paper.

LOGOS, Universitat de Barcelona

\section{ACKNOWLEDGEMENTS}

I want to thank the organizers and the audience of the seminars "Iconicity. II" (EHESS, Paris) and "Ontology and the Arts" (Laboratory for Ontology, University of Turin) where I presented previous versions of this paper. As acknowledged in previous notes, I am grateful to the anonymous referees for The American Philosophical Quarterly for their insightful comments.

\section{REFERENCES}

Burge, Tyler. 1977. "Belief De Re," The Journal of Philosophy, vol. 74, pp, 338-362.

Danto, Arthur. 1981. The Transfiguration of the Commonplace: A Philosophy of Art (Cambridge, MA: Harvard University Press).

Davies, David. 2010. "Multiple Instances and Multiple 'Instances," The British Journal of Aesthetics, vol. 50, no. 4, pp. 411-426;

Derrida, Jacques. 1987. The Truth in Painting (Chicago, University of Chicago Press). (Original edition: La Vérité en peinture, Paris: Flammarion, 1978).

Firestone, Chaz, and Scholl, Brian J. 2016. "Cognition Does not Affect Perception: Evaluating the Evidence for 'Top-Down' Effects," Behavioral and Brain Sciences, vol. 39.

García-Carpintero, Manuel. Forthcoming. "How to Understand Rule-Constituted Kinds."

Goodman, Nelson. 1968. Languages of Art: An Approach to a Theory of Symbols (Indianapolis: BobbsMerrill). 
Haugeland, John. 1991. "Representational Genera," in Philosophy and Connectionist Theory, eds. William Ramsey, David E. Rumelhart, Stephen P. Stich (Hillsdale: Lawrence Erlbaum).

Heidegger, Martin. 1964. "The Origin of the Work of Art." in Philosophies of Art and Beauty, eds. Albert Hofstadter, Richard Kuhns (New York: Random House), pp. 649-701. (Original edition: "Der Ursprung des Kunstwerkes”, in Holzwege, Frankfurt: Klostermann, 1972)

Hopkins, Robert. 1998. Picture, Image and Experience: A Philosophical Inquiry (Cambridge and New York: Cambridge University Press).

Husserl, Edmund. 2005. "Phantasy, Image Consciousness, and Memory," (1898-1925), translated by J. Brough. Collected Works, Vol. XI (Dordrecht: Springer).

Kaplan, David. 1989. "Demonstratives," in Themes from Kaplan, ed. Joseph Almog, John Perry, and Howard Wettstein (Oxford, UK: Oxford University Press), pp. 481-563.

Kulvicki, John. 2006. On Images: Their Structure and Content (Oxford: Clarendon).

Kulvicki, John. Forthcoming. Modeling the Meanings of Pictures.

Lopes, Dominic. 1996. Understanding Pictures (Oxford: Clarendon).

Mion, Regina-Nino. 2019. "Threefold Pictorial Experience and Aesthetic Attitude," in The Pleasure of Pictures. Pictorial Experience and Aesthetic Appreciation, eds. Jérôme Pelletier and Alberto Voltolini (New York: Routledge), pp. 107-124.

Nanay, Bence. 2018. “Threefoldness,” Philosophical Studies vol. 175 no.1, pp. 163-182.

Newall, Michael. 2011a. "Pictures and the Standard of Correctness," Esthetica. (www.estheticatijdschrift.nl/magazine/(2011)/depiction/pictures-and-standard-correctness).

Newall, Michael. 2011b. What Is a Picture? Depiction, Realism, Abstraction (London: Palgrave Macmillan).

Panofsky, Erwin. 1955. Meaning in the Visual Arts (Garden City, NY: Doubleday).

Putnam, Hilary. 1975. "The Meaning of 'Meaning," in Mind, Language and Reality; Philosophical Papers Volume 2 (Cambridge: Cambridge University Press), pp. 215-71. 
Schapiro, Meyer. 1968. "The Still Life as a Personal Object - A Note on Heidegger and van Gogh," in The Reach of Mind: Essays in Memory of Kurt Goldstein, ed. Marianne L. Simmel (Dordrecht: Springer), pp. 203-209.

Schier, Flint. 1986. Deeper into Pictures (Cambridge: Cambridge University Press).

Rawls, John. 1955. “Two Concepts of Rules,” The Philosophical Review, vol. 64, pp. 3-32.

Searle, John. 1969. Speech Acts: An Essay in the Philosophy of Language (Cambridge: Cambridge University Press).

Sontag, Susan. 1977. On Photography (New York: Farrar, Straus and Giroux).

Voltolini, Alberto. 2015. A Syncretistic Theory of Depiction (London: Palgrave Macmillan).

Walton, Kendall. 1990. Mimesis as Make-Believe (Cambridge, MA: Harvard University Press).

Wiesing, Lambert. 2009. Artificial Presence (Palo Alto: Stanford University Press).

Williamson, Timothy. 1996. “Knowing and Asserting.” Philosophical Review, vol. 105, pp. 489-523.

Wollheim, Richard. 1974. "On Drawing an Object," in On Art and the Mind (Cambridge, MA: Harvard University Press), pp. 3-30.

Wollheim, Richard. 1980. Art and its Objects: An Introduction to Aesthetics, 2nd edn. Revised (New York: Harper and Row).

Zeimbekis, John. 2012. "Digital Pictures, Sampling, and Vagueness: The Ontology of Digital Pictures," The Journal of Aesthetics and Art Criticism, vol. 70, no. 1, pp. 43-53. 
i Thanks to John Zeimbekis for leading me to consider how much the kind-standard can be entrenched in practices, and to Martina Federico for drawing my attention to Sontag's book.

ii Including world in the standpoint-standard does not entail that pictures express contents which are world-bound, hence always necessarily true. The world parameter just provides viewers with a spatiotemporal framework in which they can locate the events they see, without any commitment on whether those events necessarily happen in that framework. Therefore, a viewer who abides by the standard of correctness might still say, looking at a picture, "what it depicts could have failed to be the case" even though the world is a parameter of the standpoint-standard of that picture. Thanks to an anonymous referee for leading me to consider this objection.

iii Thanks to Alberto Voltolini for helping me to acknowledge the feature-standard in addition to the other three sorts of standard. Interestingly, the feature-standard involves a distinction, that between features the are ascribed to the subject depicted and those the latter is only endowed with, which matches Edmund Husserl's (2005) distinction between analogizing and non-analogizing moments of a picture (see Mion 2019, p. 117).

iv Thanks to a referee for leading me to clarify that the four categories do not individuate four different ways of seeing-in but only four different ways of supplementing seeing-in with non-pictorial information. I will develop this point further in section 6.

v I am hereby endorsing only the first half of Walton's claim that pictures are games of make-believe. That is, I agree with him that picture are games, but I do not want commit myself to his claim that they are games of make-believe.

vi This distinction between picture and image in inspired by that proposed by Hopkins in his book Picture, Image and Experience (1998), in which he distinguishes between pictures as public artifacts and images as figments of the imagination. What matters, from my perspective, is that the former have a historical and normative dimension that the latter lack. 
vii Thanks to a referee for drawing my attention to the possibility of applying Kaplan's distinction to pictures. For a thorough application of Kaplan's semantics to pictures, see Kulvicki, forthcoming.

viii Thanks to Manuel García-Carpintero for drawing my attention to this case.

ix Voltolini $(2015$, p. 72) makes a similar point when he writes: "Upon closer examination, we find that it is not the case that the aboutness of an opaque picture in question is always settled by authorial intentions. Let us consider the famous moai figures, found on Easter Island. We take them to be statues representing the gods of the Polynesian community living on the island before its discovery by the Europeans. Yet who knows? Maybe the artists who sculpted the moai had altogether different intentions. [...] Hence, already in the case of opaque pictures, their intentional aboutness is a matter of negotiation between their producers and their consumers".

x On the notion of deference to epistemic authorities see Putnam (1975) and Burge (1977). 